\title{
Closed Loop Analysis of Single-Inductor Dual-Output Buck Converters with Mix-Voltage Conversion
}

\author{
Tomina Thomas ${ }^{1}$, T. Jothi ${ }^{2}$ \\ ${ }^{1} M$ E Student, PITAM, Chennai, TamilNadu, India \\ ${ }^{2}$ Senior Lecturer, Department of Electrical and Electronics Engineering, PITAM, Chennai, TamilNadu, India
}

\begin{abstract}
A single-inductor dual-output (SIDO) buck converter has recently found applications in hand-held battery-powered electronic devices. The circuit operation and the functional interdependencies among basic converter parameters such as dc voltage gains, transistor duty cycles, and load current levels are much more complicated than those of the single-output counterpart. In this project, a rigorous analysis was conducted to develop dc equations in steady state operation for SIDO converters. More importantly, from the analysis results, a possibility of a new mode of operation, dubbed "mix-voltage" operation, will be pointed out. In the so-called "mix-voltage" operation, the converter is capable of working even when the input voltage is lower than one of the two output voltages. In the past, a SIDO buck converter has been used for providing "pure-buck" outputs, i.e., both output voltages are lower than the input voltage. Therefore, this possibility not only opens up new applications but also extends the operating battery range in existing applications. Experimental results confirmed the dc equations and the "mix-voltage" conversion of SIDO buck converters.
\end{abstract}

Keywords- DC Power converters, mix-voltage conversion, single inductor dual output (SIDO).

\section{Introduction}

A single-inductor dual-output buck converter has recently found applications in hand-held batterypowered electronic devices, which require dual outputs but no electrical isolation.The main attraction of a SIDO lies in the fact that dual regulated outputs can be provided with relatively low cost and small size. Fig. 1 shows the power circuit diagram of a SIDO buck converter.The circuit diagram may look simple but the circuit operation and the functional interdependencies among basic converter parameters such as dc voltage gains, transistor duty cycles, and load current levels are much more complicated than the counterparts of a conventional single-output buck converter.In this paper, rigorous analysis in steady-state operation would be conducted to develop useful equations for design purposes. More importantly, from the analysis results, a possibility of a new mode of operation, "mix-voltage" operation would be pointed out.

In the so-called "mix-voltage" operation,the input voltage can be lower than one of the output voltages, as opposed to conventional "pure-buck" operation in which input voltage must be higher than both output voltages. This implies that the input battery may operate down to a voltage level lower than previously thought possible. This may also mean that single battery, instead of two in series, is sufficient in some applications.In the paper, a basic review of SIDO buck converter willbe given first. Analytical equations relevant to continuous and discontinuous conduction mode, dc voltage gains, and duty cycles will be developed for both the "purebuck" and the "mix-voltage" operations.An equation will also be derived to estimate whether a mix-voltage conversion is possible for given specifications. Since a SIDO buck converter is mostly used in lowvoltage applications, semiconductor switch conduction voltage drops will be included in the analysis for accuracy.

\section{Literature Review}

A basic review of SIDO buck converter will be given first. Analytical equations relevant to continuous and discontinuous conduction mode, dc voltage gains, and duty cycles will be developed for both the "purebuck" and the "mix-voltage" operations An equation will also be derived to estimate whether a mix-voltage conversion is possible for given specifications. Since a SIDO buck converter is mostly used in low voltage applications, semiconductor switch conduction voltage drops will be included in the analysis for accuracy. Experimental results will also be shown to validate the analytical results. Literature survey gives an overview about these proposed systems. These are the supporting papers of my work. This literature survey extracts information from some of the literature available on this subject. It does not claim to be complete nor does it take a position towards the opinions expressed in these concepts.

\section{Operation of SIDO Buck Converter}

A SIDO buck converter can be operated in both the continuous conduction mode and discontinuous conduction mode just like a conventional single-output buck converter. Fig. 2 shows the waveforms of the inductor current and transistor duty cycles with a time multiplexing control scheme for both the CCM and DCM 
operations. According to the relative magnitude of transistor $\mathrm{Q}_{1}$ duty cycle $\mathrm{D}_{1}$ and transistor $\mathrm{Q}_{2}$ duty cycle $\mathrm{D}_{2}$, the waveforms are given for three cases: Case A $\left(D_{1}<D_{2}\right)$, Case B $\left(D_{1}=D_{2}\right)$, and Case $C\left(D_{1}>D_{2}\right)$. In the CCM operation, there are three periods: T1 is the duration when both transistors Q1 and Q2 are ON. During this period, diodes $\mathrm{Da}$ and $\mathrm{Db}$ are OFF and the power is provided to $\mathrm{V}_{\mathrm{O} 1}$ only. The period $\mathrm{T} 2$ is the period when only one of the transistors is in conduction. If Q1, instead of Q2, is in conduction, then the inductor current flows through $\mathrm{Db}$ and the power is provided to $\mathrm{V}_{\mathrm{O} 2}$ only. Otherwise, it flows through $\mathrm{Da}$ and the power is provided to $\mathrm{V}_{\mathrm{O} 1}$ only. The period $\mathrm{T}_{3}$ is the period when both transistors are OFF. The inductor current is then flowing through $\mathrm{Da}$ and $\mathrm{Db}$, and the power is provided only to $\mathrm{V}_{\mathrm{O} 2}$. Notice that $\mathrm{D} 1$ is, therefore, equal to $\mathrm{T}_{1} / \mathrm{T}_{\mathrm{S}}$ or $\left(\mathrm{T}_{2}+\right.$ $\left.T_{2}\right) / T_{S}$, where $T_{S}$ is the conversion switching period, depending upon whether it is Case $A, B$, or $C$. The same situation applies to D2. It is also clear that there is no $\mathrm{T}_{2}$ period for Case B. All of these are shown along with the waveforms in Fig. 2. For the DCM operation, there is an additional period $T_{d}$ when the inductor current stays at zero and none of the switches is on. The duty cycle $D_{d}$ is defined as $T_{D} / T_{S}$.

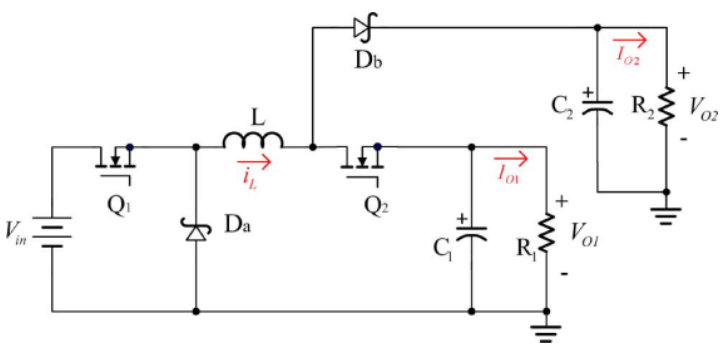

Fig.1 SIDO buck converter circuit diagram

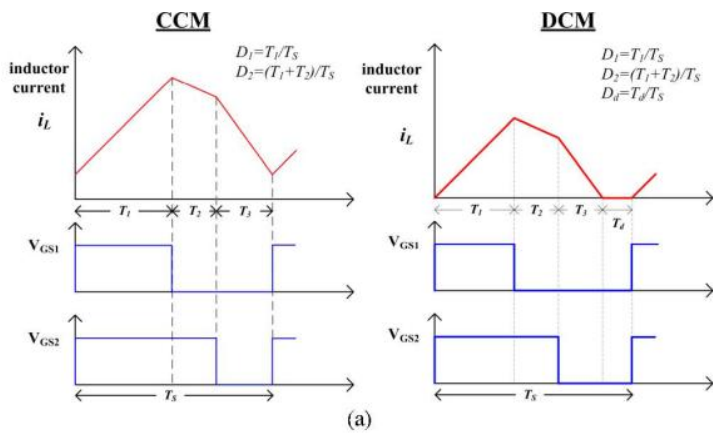

CCM
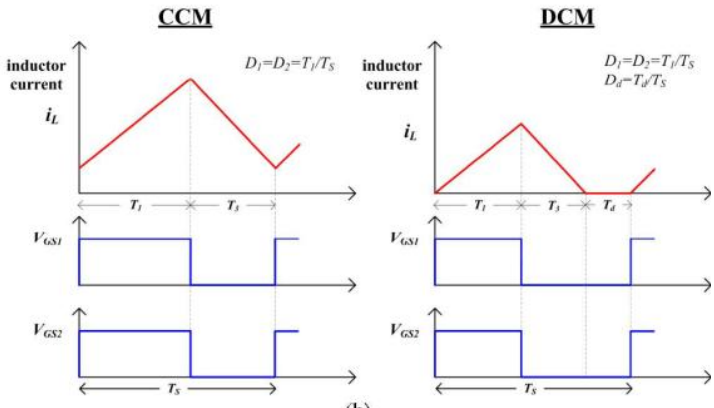

(b)
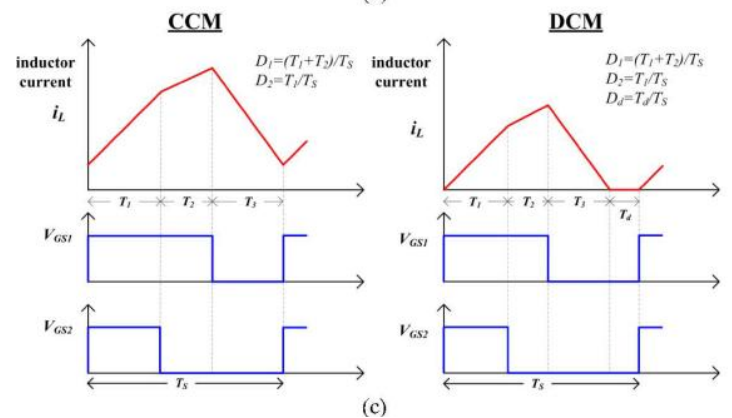

Fig.2 Operating waveforms of a SIDO buck converter 


\section{SIDO Buck Converter De Equations}

In this section, dc equations of the SIDO converters in steady state operation will be derived. The derivation starts with an inductor current waveform that varies according to the case of converter operation described in Section II. Only Case A will be used as an example for detailed derivation. As mentioned earlier, semiconductor switch conduction voltage drops will be included in the derivation. From the waveform, the input average current $I$ in is the average of the $Q 1$ current, i.e., the area below the inductor current waveform during the $T 1$ period divided by the total period $\mathrm{T}_{\mathrm{S}}$. This leads to (1). Similarly, (2) can be obtained by equating the output current $\mathrm{I}_{\mathrm{O} 1}$ to the average of the inductor current of the $\mathrm{Q} 2$ current. And (3) can be obtained by equating the output current $\mathrm{I}_{\mathrm{O} 2}$ to the average of the $\mathrm{D}_{\mathrm{b}}$ current. In the equations, $\mathrm{V}_{\text {in }}$ is the input voltage, $\mathrm{V}_{\mathrm{D}}$ and $\mathrm{V}_{\mathrm{DS}}$ are, respectively, the conduction voltage drops of diodes and transistors, and $\mathrm{V}_{\mathrm{O} 1}$ and $\mathrm{V}_{\mathrm{O} 2}$ are the output voltages. $\mathrm{I}_{\mathrm{X}}$ is the valley of the inductor current as shown in Fig. 3, and $\mathrm{T}_{\mathrm{S}}$ is the conversion switching period.

$$
\begin{aligned}
& \mathrm{I}_{\text {in }}=T_{\mathrm{S}} / 2 \mathrm{~L}\left(\mathrm{~V}_{\mathrm{in}}-2 \mathrm{~V}_{\mathrm{DS}}-\mathrm{V}_{01}\right) \mathrm{D}_{21}+\mathrm{I}_{\mathrm{X}} \mathrm{D}_{1} \\
& \mathrm{I}_{01}=\mathrm{T}_{\mathrm{S}} / 2 \mathrm{~L}\left[\mathrm{~V}_{\mathrm{in}} \mathrm{D}_{1}\left(2 \mathrm{D}_{2}-\mathrm{D}_{1}\right)-\mathrm{V}_{\mathrm{O} 1} \mathrm{D}_{2}^{2}++\mathrm{V}_{\mathrm{DS}}\left(\mathrm{D}^{2}{ }_{1}-2 \mathrm{D}_{1} \mathrm{D}_{2}{ }^{2}\right)-\mathrm{V}_{\mathrm{D}}\left(\mathrm{D}_{2}-\mathrm{D}_{1}\right)^{2}\right]+\mathrm{I}_{\mathrm{X}} \mathrm{D}_{2}(2) \\
& \mathrm{I}_{02}=\mathrm{T}_{\mathrm{S}} / 2 \mathrm{~L}\left(\mathrm{~V}_{02}+2 \mathrm{~V}_{\mathrm{D}}\right)\left(1-\mathrm{D}_{2}{ }^{2}\right)+\mathrm{I}_{\mathrm{X}}\left(1-\mathrm{D}_{2}\right) \\
& \mathrm{V}_{\text {in }} \mathrm{I}_{\mathrm{in}}=\mathrm{V}_{01} \mathrm{I}_{01}+\mathrm{V}_{02} \mathrm{I}_{02}+\mathrm{V}_{\mathrm{DS}}\left(\mathrm{I}_{\mathrm{in}}+\mathrm{I}_{\mathrm{O} 1}\right)+\mathrm{V}_{\mathrm{D}}\left(2 \mathrm{I}_{\mathrm{O} 2}+\mathrm{I}_{\mathrm{O} 1}-\mathrm{I}_{\mathrm{in}}\right)
\end{aligned}
$$

Using the principle of conservation of energy, (4) can be obtained, where the left-hand side is the total input power, the first two terms of the right-hand side represent the total output power, and the remaining two terms are the power losses of the MOSFET and diode switches. From the four simultaneous equations (1)-(4), the two variables IX and Iin can be eliminated. Two independent equations remain. These two independent equations can be simplified further using (5), which can be obtained from a consideration of the inductor volt-second balance in the steady state.

$\left(\mathrm{V}_{\mathrm{in}}-\mathrm{V}_{\mathrm{O} 1}-2 \mathrm{~V}_{\mathrm{DS}}\right) \mathrm{D}_{1}=\left(\mathrm{V}_{\mathrm{O} 1}+\mathrm{V}_{\mathrm{DS}}+\mathrm{V}_{\mathrm{D}}\right)\left(\mathrm{D}_{2}-\mathrm{D}_{1}\right)+\left(\mathrm{V}_{\mathrm{O} 2}+2 \mathrm{~V}_{\mathrm{D}}\right)\left(1-\mathrm{D}_{2}\right)$

DC equations for Case A of CCM can then be obtained as (6) and (7). Group I in CCM consists of variables $V_{O I}$, $V_{O 2}, D_{1}$, and $D_{2}$; Group II consists of converter component values $V_{D}, V_{D S}$, and $L$; and Group III consists of converter operating conditions $T_{S}, I_{O I}, I_{O 2}$, and $V_{\text {in }}$. Normally, the values of the latter two groups are given. The values $D_{1}$ and $D_{2}$ can then be found by solving the two simultaneous (6) and (7), if the values of $V_{O I}$ and $V_{O 2}$ are specified. On the other hand, the values $V_{01}$ and $V_{02}$ can be found by solving the same set of equations, if the values $D_{1}$ and $D_{2}$ are specified. The DC equations for the other two Cases of CCM operation can be obtained in a similar fashion. It should be pointed out that besides the equation complexity, the voltage gains in a SIDO

\begin{tabular}{|c|c|c|}
\hline Case & DC equations in CCM & \\
\hline Case $\mathrm{A}\left(D_{l}<D_{2}\right)$ & 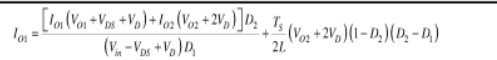 & (6) \\
\hline or $\begin{array}{l}\text { or } \\
\text { Case }\left(D_{l}=D_{2}\right)\end{array}$ & 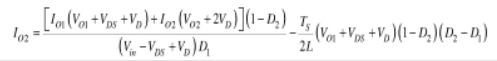 & (a) \\
\hline \multirow{2}{*}{$\operatorname{Case} \mathrm{C}\left(D_{1}>D_{2}\right)$} & 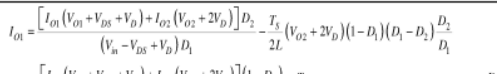 & (8) \\
\hline & 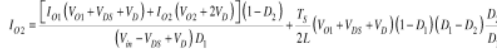 & (9) \\
\hline
\end{tabular}
converter depend not only on duty cycles but also on inductor value, load currents, and switching period.

Table I

Dc Equations of A SIDO Buck Converter in CCM

The DC equations of a SIDO converter in DCM operation will be derived as follows. Compared to a CCM operation, there are two differences in writing the equations for DCM operation. First, $I_{X}$ is zero and an additional variable, duty cycle $D_{d}$, is involved. Setting $I X$ equal to zero and including the variable $D_{d}$ in (2) and (3) leads, respectively, to (10) and (11).From the consideration of the inductor volt second balance in the steady-state DCM operation, (12) can be obtained. 
TABLE II: DC EQUATIONS OF A SIDO BUCK CONVERTER IN DCM

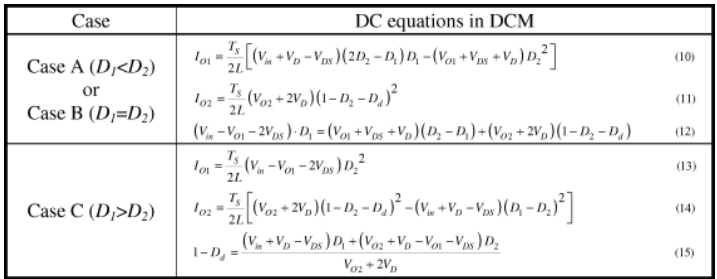

\section{Mix-Voltage Conversion for SIDO Buck Converter}

Three examples will be given. From the results, one can also see if "mix-voltage" conversion is possible for the specifications.

Example 1: Converter specifications are given in thefollowing. $V_{O 1}=1.8 \mathrm{~V}, V_{02}=3.3 \mathrm{~V}, I_{O 1}=500 \mathrm{~mA}, I_{O 2}=$ $200 \mathrm{~mA}, L=10 \mu \mathrm{H}, V_{D S}=0.01 \mathrm{~V}, V_{D}=0.4 \mathrm{~V}$, and $T_{S}=5 \mu \mathrm{s}$. The maximum input voltage $V_{\text {in }} \max =5 \mathrm{~V}$. Find the duty cycle information and the minimum operable input voltage $V_{\text {in }} \min$. Step $1: V_{\text {in }}$ is first set at $5 \mathrm{~V}$ and proceeded as follows: Two sets of solutions are obtained using (13)-(15). $\left(D_{1}, D_{2}, D_{d}\right)=\{(-0.6763,-0.7931$, $2.255)$ and $(0.6763,0.7931,-0.2546)\}$. MATHCAD software was used for solving the simultaneous equations. Step 2: Since $D_{d}$ is outside the range of $[0,1]$ for both solutions, the converter works in CCM; therefore, go to Step C3.Step C3: One set of solution is obtained $\left(D_{1}, D_{2}\right)=(0.5335,0.6478)$ using (8) and (9). Step C4: $D_{1}$ and $D_{2}$ stay within boundary. Step C5: Need to check if $D_{1}>D_{2}$. It turns out $D_{1}$ is less than $D_{2}$. This means the assumption in Step C3 and the equation used to obtain $D_{1}$ and $D_{2}$ were incorrect. Therefore, go to Step C7. The duty cycles need to be recalculated. Step C7: Solving for $D_{1}$ and $D_{2}$ using (6) and (7). $\left(D_{1}, D_{2}\right)=(0.5268$, 0.6670 ). The data given earlier were obtained for $V_{\text {in }}=5 \mathrm{~V}$. For each selected $V_{\text {in }}$ value, the operating duty cycle values can be found as described earlier. It turns out that the converter operates in the CCM for the entire input range. As $V_{\text {in }}$ is decreased, the $D_{1}$ curve intersects with the $D_{1}=1$ line at $V_{\text {in }}$ min. This crossover point is the minimum input voltage that the converter specifications can still be met by the converter because $D_{1}$ must be no more than unity. From the figure, $V_{\text {in }}$ min is about $2.36 \mathrm{~V}$, which lies between $V_{O I}$ and $V_{O 2}$. So, mix-voltage conversion exists in this example. This example shows that the converter is capable of operating even when the input battery voltage is well below $V_{O 2}$ value of $3.3 \mathrm{~V}$.

Example 2: The converter specifications are the same as those of Example 1 with the exception of the load current values: $I_{O I}=100 \mathrm{~mA}$ and $I_{O 2}=500 \mathrm{~mA}$. In this case, the converter operates in the CCM also for the entire input voltage range. However, $V_{\text {in }} \min$ is greater than both output voltages, which implies that mix-voltage conversion is not possible.

Example 3: The converter specifications are the same as those of Example 1 except that the load current levels are smaller: $I_{O I}=50 \mathrm{mAand} I_{O 2}=20 \mathrm{~mA}$. By applying the same procedure, it was found that this is a DCM case.

\section{CONCLUSION}

A SIDO buck converter was analyzed for steady-state operation. The various operating modes were explored and design equations were developed. These equations allow the designer to find out intricate relationships among output voltages, transistor duty cycles, and output currents. From the results, a mix-voltage operation was pointed out and demonstrated. This new mode of operation opens up new applications and may also extend the input battery operable range for existing applications.

\section{References}

[1]. STw4141 single-coil dual-output step-down DC/DC converter for digital base band and multimedia processor supply data sheet," ST Microelectron., Jun. 2006.

[2]. K.-Y. Lin, C.-S. Huang, D. Chen, and K. H. Liu, "Modeling and design of feedback loops for a voltage-mode single-inductor dualoutput buck converter," in Proc. IEEE Power Electron. Spec. Conf., 2008, pp. 3389-3395.

[3]. E. Bonizzoni, F. Borghetti, P. Malcovati, F. Maloberti, and B. Niessen, "A 200Ma 93\% peak efficiency single-inductor dual-output DC-DC buck converter," in Proc. IEEE Solid-State Circuits Conf., 2007, pp. 526-619.

[4]. D. Goder and H. Santo, "Multiple output regulator with time sequencing,"U.S Patent 5,617,015, Apr. 1997.

[5]. M. Belloni, E. Bonizzoni, and F. Maloberti, "On the design of single inductor multiple-output DC-DC buck converters," in Proc. IEEE Int.mp. Circuits Syst., 2008, pp. 3049-3052

[6]. W. Xu, X. Zhu, Z. Hong, and D. Killat, "Design of single-inductor dual output switching converters with average current mode control," in Proc.IEEE Asia Pac. Circuits Syst. Conf., 2008, pp. 902-905.

[7]. K. Xing, F. Liu, X. Cheng, and H.C. Du, "Real-Time Detection of Clone Attacks in Wireless Sensor Networks," Proc. IEEE Int'l Conf. Distributed Computing Systems (ICDCS), pp. 3-10, June 2008.

[8]. A. Pizzutelli and M. Ghioni, "Novel control technique for single inductor multiple output converters operating in CCM with reduced cross-regulation," in Proc. IEEE Appl. Power Electron. Conf., 2008, pp. 1502-1507.

[9]. P. Patra, A. Patra, and D. Kastha,"On-chip implementation of a multi output voltage regulator based on single inductor buck converter topology,’Proc. IEEE Embedded Syst. Conf., 2007, pp. 935-940. 
[10]. D. Ma,W. H. Ki, C. Y. Tsui, and P. K. T. Mok, "Single-inductor multiple output switching converters with time-multiplexing control in discontinuous conduction mode," IEEE J. Solid-State Circuits, vol. 38, no. 1. 89-100, Jan. 2003.

[11]. W. H. Ki and D. Ma, "Single-inductor multiple-output switching converters," in Proc. IEEE Power Electron. Spec. Conf., 2001, pp. 226-231.

[12]. D. Trevisan, W. Stefanutti, P. Mattavelli, and P. Tenti, "FPGA control of SIMO DC-DC converters using load current estimation," in Proc. IEEE Ind. Electron. Soc. Conf., 2005, pp. 2243-2248.

[13]. T. Li, “Single inductor multiple output boost regulator,” U.S. Patentb6, 075,295, Jun. 2000. 